This document is confidential and is proprietary to the American Chemical Society and its authors. Do not copy or disclose without written permission. If you have received this item in error, notify the sender and delete all copies.

\title{
Understanding and Controlling Chemical Modifications of Rubicene for Their Envisioned Use as Molecular Organic Semiconductors
}

\begin{tabular}{|r|l|}
\hline Journal: & The Journal of Physical Chemistry \\
\hline Manuscript ID & jp-2016-10566b \\
\hline Manuscript Type: & Article \\
\hline Date Submitted by the Author: & $19-$ Oct-2016 \\
\hline Complete List of Authors: & $\begin{array}{l}\text { Moral, Mónica; University of Castilla-La Mancha, Renewable Energy } \\
\text { Research Institute } \\
\text { Pérez-Jiménez, Ángel; Universidad de Alicante, Departamento de Química- } \\
\text { Física } \\
\text { Sancho-García, Juan Carlos; University of Alicante, Physical Chemistry }\end{array}$ \\
\hline
\end{tabular}

\section{SCHOLARONE ${ }^{\text {m }}$ \\ Manuscripts}


1

2

3

4

5

6

7

8

9

10

11

12

13

14

15

16

17

18

19

20

21

22

23

24

25

26

27

28

29

30

31

32

33

34

35

36

37

38

39

40

41

42

43

44

45

46

47

48

49

50

51

52

53

54

55

56

57

58

59

60

\author{
Understanding and Controlling Chemical Modifications of Rubicene for Their Envisioned Use as \\ Molecular Organic Semiconductors \\ M. Moral, ${ }^{1,2 *}$ A. J. Pérez-Jiménez, ${ }^{1}$ J.C. Sancho-García. ${ }^{1}$ \\ ${ }^{1}$ Departamento de Química Física, Universidad de Alicante, E-03080, Alicante, Spain. \\ ${ }^{2}$ Renewable Energy Research Institute, University of Castilla-La Mancha. Paseo de la Investigación 1, 02071, Albacete, Spain \\ *Corresponding-author: monicamoralm@gmail.com
}

\begin{abstract}
We theoretically discuss here the relationship between the structure of a set of halogenated and cyanated molecules containing the rubicene moiety, and a set of relevant electronic properties related to the opto-electronic and semiconductor character of these systems, namely: frontier molecular orbital shape and energy levels, electron affinity, ionization potential, reorganization energy, and electronic coupling between neighboring dimers, calculated over experimental (x-ray) or simulated crystal structures. To do it, we always employ accurate and validated Density Functional Theory methods. The obtained results will be compared with some reference organic semiconductor systems, in order to determine the potential use of the studied compounds in the fabrication of opto-electronic devices.
\end{abstract}




\section{INTRODUCTION}

One of the main challenges in the field of Nanoelectronics is the development of new materials to be efficiently used in opto-electronic devices such as organic field-effect transistors (OFETs), organic light-emitting diodes (OLEDs) or solar cells, and, more recently, in organic radiofrequency identification (RFID) tags, biosensor or

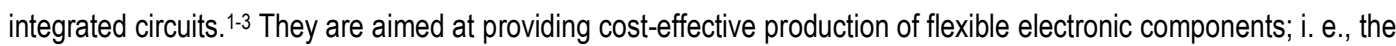
fabrication of devices over large areas and lightweight flexible substrates with a high charge-carrier mobility of the semiconductor materials used within the active layer. In the last years, intense and worldwide efforts are focused on the use of carbon-based materials, such as acenes, ${ }^{4}$ fullerenes, ${ }^{5,6}$ graphene nanoribbons, ${ }^{7,8}$ nanorings, ${ }^{8}$ etc., acting as organic semiconductors able to compete with inorganic materials. In that sense, the set of molecules known as polycyclic aromatic hydrocarbons (PAHs) have been widely used, due to their high charge mobility $\left(\mu>1 \mathrm{~cm}^{2} \mathrm{~V}^{-1} \mathrm{~s}^{-1}\right)$ mainly attributed to a favored $\pi-\pi$ stacking between adjacent molecules, thus resulting in strong electronic coupling between them. An interesting example of $\mathrm{PAH}$, not yet fully explored, is provided by rubicene $\left(\mathrm{C}_{26} \mathrm{H}_{14}\right)$ (figure 1a) whose backbone consists of five rings with three linearly fused rings and one benzene ring at each diagonal side, thus keeping a planar m-orbital surface. Note that this molecule has been used as a p-type semiconductor in bilayer organic solar cells ${ }^{10}$ and also constitutes a nanofragment of fullerenes. Moreover, dibenzo[a,m]rubicene $\left(\mathrm{C}_{34} \mathrm{H}_{18}\right)$ has also been synthesized as a cyclo-penta-fused PAH, resulting of the fusion of two benzene rings to rubicene (figure 1b). ${ }^{11}$

However, as far as we know, no systematic studies about rubicene or its derivatives have been carried out. We have thus studied in this work, from a theoretical point of view: i) the structural and electronic changes (see figure 1) induced by the systematic introduction of substituents or fused-benzene rings at selected positions; ii) the semiconductor properties of all the pristine and the newly derived systems, attempting to set up their promising role in the fabrication of devices, acting possibly as ambipolar semiconductors, and trying thus to establish structureproperties relationships from isolated to crystalline samples.

a)<smiles></smiles>

$\mathrm{R}=\mathrm{X}=\mathrm{H} \rightarrow$ Rubicene

$\mathrm{R}=\mathrm{X}=\mathrm{F}, \mathrm{Cl}, \mathrm{Br}, \mathrm{CN} \rightarrow$ per-substituted derivatives

$\mathrm{R}=\mathrm{H} ; \mathrm{X}=\mathrm{F}, \mathrm{Cl}, \mathrm{Br}, \mathrm{CN} \rightarrow[8]$ - substituted derivatives

$\mathrm{R}=\mathrm{F}, \mathrm{Cl}, \mathrm{Br}, \mathrm{CN} ; \mathrm{X}=\mathrm{H} \rightarrow[6]$ - substituted derivatives b)

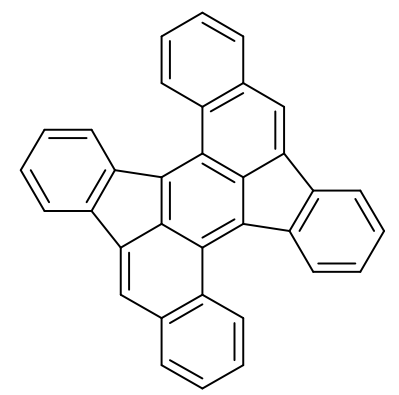

Dibenzo[a,m]rubicene

Fig. 1. Chemical structure of rubicene and its derivatives (left) and dibenzorubicene (right)

\section{THEORETICAL CONSIDERATONS}

In typical T-conjugated organic crystals with small bandwidths $(<1 \mathrm{eV})$ and at room temperature, the charge motion generally occurs by a hopping mechanism, which can be described as a self-exchange charge-transfer (CT) 
reaction between two identical molecules in the absence of an external electric field. This self-exchange $C T$ process is generally described within the framework of the Marcus-Levich-Jortner (MLJ) ${ }^{12,13}$ model, which expresses the rate constant for charge transfer $\left(k_{c}\right)$ as:

$$
k_{C T}=\frac{4 \pi^{2}}{\hbar} V_{i f}^{2} \sqrt{\frac{1}{4 \pi \lambda_{0} k_{B} T}} \sum_{n=0}^{\infty}\left[\exp \left(-S_{e f f}^{n}\right) \times \frac{S_{e f f}^{n}}{n !} \times \exp \left(\frac{-\left(\lambda_{0}+n \hbar \omega_{e f f}+\Delta G^{\ominus}\right)^{2}}{4 \lambda_{s} k_{B} T}\right)\right]
$$

where $k_{B}$ and $\hbar$ are the Boltzmann's and Planck's constants, respectively; $T$ is the temperature, fixed here at 298.15 $\mathrm{K} ; V_{\text {if }}$ and $\lambda_{0}$ stand for, respectively, the charge transfer integral and the classical contribution (mostly the external) to the reorganization energy, fixed the latter here at $0.1 \mathrm{eV}$ according to previous estimates, ${ }^{14,15}$ and $\Delta G^{\theta}$ is the energy difference between the electronic states involved in the charge transfer process (equal to zero in the self-exchange process). In the MLJ formalism, a single effective mode with an energy $\hbar$ weff, which represents all the intramolecular modes, is treated at the quantum-mechanical level via the effective Huang-Rhys factor Seff $=\lambda i / \hbar \omega$ eff ( $\hbar \omega$ eff was set here equal to $0.2 \mathrm{eV}$, which is the typical energy of $\mathrm{C}-\mathrm{C}$ stretching modes). ${ }^{16-18}$ In contrast, the intermolecular modes are treated classically through the $\lambda_{0}$ parameter. Generally speaking, in organic crystals, the outer contribution is of the order of a tenth of an electronvolt or, even, lower, contrary to charge transfer processes in solution wherein the external part dominates. ${ }^{19-22}$ Different values for $\lambda_{0}$, ranging between 0.01 and $0.2 \mathrm{eV}$, have been proposed and employed in the literature. ${ }^{23-26}$. In that sense, as we commented above, $\lambda_{0}$ has been fixed at $0.1 \mathrm{eV}$ in order to facilitate the comparison with previous rate constants. ${ }^{14,15}$

Despite some limitations imposed by the approximations used to derive equation (1), such as $V_{\text {if }}<<\lambda$, or single promoting frequency and high temperature limit, it becomes clear how two key magnitudes govern semiquantitatively the charge transport in organic crystals. The first one is the reorganization energy, divided in two contributions: internal (which includes only the reorganization energy of the molecules involved in charge transfer) and external (which accounts for any environmental relaxation and changes upon charge hopping) reorganization energy. As we commented above, the external reorganization energy is fixed at $0.1 \mathrm{eV}$, while the internal, $\lambda_{\text {i, }}$ is calculated using density functional theory (DFT). Thus, $\lambda_{i}$ can be determined, for self-exchange process, as a sum of two terms which corresponds to the geometry relaxation energies upon going from the neutral-state geometry to the charged-state one and vice versa (Nelsen four-point method) ${ }^{27,28}$

$$
\begin{aligned}
& \lambda_{i}=\lambda_{1}+\lambda_{2} \\
& \lambda_{1}=E^{0}\left(G^{*}\right)-E^{0}\left(G^{0}\right) \\
& \lambda_{2}=E^{*}\left(G^{0}\right)-E^{*}\left(G^{*}\right)
\end{aligned}
$$

where $E^{0}\left(G^{0}\right)$ and $E^{*}\left(G^{*}\right)$ are the ground-state energies of the neutral and ionic states, respectively. $E^{0}\left(G^{*}\right)$ is the energy of the neutral molecule at the optimal ionic geometry, and $E^{*}\left(G^{0}\right)$ is the energy of the charged state at the optimal geometry of the neutral molecule.20-22

The second magnitude is the charge transfer integral, $V_{i f}$, which describes the strength of the electronic interactions between neighboring molecules, and it thus critically depends on their relative spatial arrangement. The electronic coupling is defined by the matrix element

$$
V_{\text {if }}=\langle\psi|H| H|\psi|>
$$

where $\hat{H}$ is the electronic Hamiltonian of the whole system and $\psi_{i}$ and $\psi_{\mathrm{f}}$ are the wave-functions of two initial and final charge-localized states, ${ }^{22,29,30}$ in the hypothetical absence of any coupling between the molecular units. ${ }^{31-33}$ However, we have determined $V_{\text {if }}$ values as one-half of the energy difference between the adiabatic potential energies at the geometry $\left(G_{c}\right)$ where the diabatic (localized) potential energy surfaces cross each other ${ }^{34,35}$ 


$$
V_{i f}=\frac{1}{2}\left[E_{+}(G)-E_{-}(G)\right]_{G=G_{C}}
$$

This two-state model involves the solution of the equation

$$
\left|\begin{array}{cc}
H_{i i}-E & H_{i j}-E S_{i f} \\
H_{f i}-E S_{f i} & H_{f f}-E
\end{array}\right|=0
$$

From which one obtains

$$
V_{i f}=\frac{1}{1-S_{i f}^{2}}\left[H_{i f}-\frac{S_{i f}\left(H_{i i}+H_{f f}\right)}{2}\right]
$$

with $\mathrm{S}_{\text {if }}=\left\langle\Psi_{i} \mid \Psi_{\mathrm{i}}\right\rangle, \mathrm{H}_{\mathrm{if}}=\left\langle\Psi_{i}|\hat{H}| \Psi_{\mathrm{f}}\right\rangle, \mathrm{H}_{\mathrm{ii}}=\left\langle\Psi_{i}|\hat{H}| \Psi_{\mathrm{i}}\right\rangle$ and similarly $\mathrm{H}_{\mathrm{ff}}$. We have used the unrestricted Hartree-Fock (UHF) wave function to describe the excess charge (both, hole and electron) localized on the initial and final states for a hole or electron transfer reaction. Note that this excess charge has been checked to remain completely localized on one (and only one) of the molecules during the set of calculations performed.

For an $n$-dimensional and spatially isotropic system, in which homogeneous charge diffusion can be assumed, the diffusion coefficient for charge-carriers (D) can be evaluated as ${ }^{29}$

$$
D=\frac{1}{2 n} \lim _{t \rightarrow \infty} \frac{\left\langle[r(t)-r(0)]^{2}\right\rangle}{t} \approx \frac{1}{2 n} \lim _{t \rightarrow \infty} \frac{\left\langle r^{2}\right\rangle}{t} \approx \frac{1}{2 n} \sum_{i} r_{i}^{2} k_{i} p_{i}
$$

(6)

where $\mathrm{n}=3$ and $i$ runs over all nearest adjacent molecules while $r_{i}, k_{i}$ are, respectively, the corresponding center-tocenter hopping distance and the electron transfer rate constant (obtained from eqn. (1)), and $p_{i}\left(=k_{i} / \sum_{i} k_{i}\right)$ is the hopping probability. ${ }^{29}$ In the low (zero) field limit, the charge carrier mobility $\left(\mu_{\text {hop }}\right)$ can be described by the EinsteinSmoluchowsky relation

$$
\mu_{\text {hop }}=\frac{e D}{k_{B} T}
$$

where $T$ is the temperature, $k_{B}$ is the Boltzmann constant, $e$ is the electron charge and $D$ is the diffusion coefficient.

The frontier MOs and the work-function $\left(\Phi_{\mathrm{m}}\right)$ of the electrode must have close values for an efficient charge injection. An ohmic contact is produced when the energy difference between the frontier $\mathrm{MO}$ and $\Phi_{\mathrm{m}}$ is equal or lower than $0.3 \mathrm{eV}$. In the case of $p$-type semiconductors, the HOMO must be energetically aligned with the Fermi levels of environmentally stable anodes, such as ITO36 to obtain an efficient hole injection. By contrast, in the case of $n$-type semiconductors, the LUMO should match the Fermi level of the electrodes with low work function, such as $\mathrm{Na}, \mathrm{Cs}$, $\mathrm{Ca}, \mathrm{Mg}, \mathrm{Ba}$ or Al. ${ }^{37}$ Note that interface dipole effects between electrode and semiconductor have not been taken into account, ${ }^{38}$ but the comparison of $\Phi_{\mathrm{m}}$ with HOMO/LUMO energy levels of the semiconductor may help to determine whether charge injection is likely or, on the contrary, if a high contact resistance should be expected. Additionally, the values of the HOMO and LUMO orbitals must range between -4.8 and $-5.5 \mathrm{eV}$, and -3.6 and $-4.5 \mathrm{eV}$, respectively, to improve the stability of the opto-electronic device..$^{21}$ There might be possible a limit value for LUMO energy in -4.0 $\mathrm{eV}$, due to the fact that negative charges can react with atmospheric oxidants such as water or oxygen.39,40

On the other hand, the ionization potential (IP), electron affinity (EA) and quasiparticle gap (QEG, calculated as the difference between the corresponding adiabatic, AIP and AEA, values) are also key parameters that determine the efficiency of the charge injection from the electrodes ant their susceptibility to be reduced or oxidized upon air exposure. ${ }^{41}$ Thus, the EA of a semiconductor must be $\geq 3.0 \mathrm{eV}$ for an easy electron injection, but not much greater than $4.0 \mathrm{eV}$ to avoid destabilization under ambient conditions. ${ }^{42}$ Low IPs facilitate hole injection but too low values can produce unintentional doping.

All these associated energy magnitudes will be also calculated here for the compounds under investigation. 


\section{COMPUTATIONAL DETAILS}

The Gaussian09 package (Release D.01) ${ }^{43}$ has been employed for the computation of the structural and electronic properties of the studied systems, employing for that the hybrid functional B3LYP44,45 together with Pople's $\left(6-31+G^{*}\right)$ basis sets. The gas-phase HOMO/LUMO eigenvalues (Eномо/ELumo), IP/EA and $\lambda_{i}$ values were extracted from the optimized (and verified) geometrical minima of the isolated systems. Closed-shell calculations for singlets and open-shell calculations for doublets (cationic and anionic species) have been carried out for the different structures. We have chosen the B3LYP model since it yields reasonable conjugated-polymer ground-state structures, ${ }^{46,47}$ and, in general, is appropriate for the prediction of electronic structures of polycyclic aromatic hydrocarbons. ${ }^{48}$ In addition, that method provides theoretical $\lambda_{i}$ energies in good quantitative agreement with the corresponding experimental values from gas phase ultraviolet photoelectron spectroscopy, ${ }^{49}$ as well as satisfactory linear relationships between calculated Eномо/ELumo and experimental IPs / EAs in such a way that the calculated Eномо/ELumo can be used to semi quantitatively estimate EAs/IPs 50.52 and orbital energies. ${ }^{53}$

The unknown crystal structures for some rubicene derivatives were modeled with the $\mathrm{PBE}^{54}$ exchangecorrelation functional and a numerical double- $\zeta+$ polarization atomic orbital basis set, where the ions are described with norm-conserving Troullier-Martins pseudopotentials, as well as with PBE using a Grimme's dipersion correction term ${ }^{55}$ with a DZP basis set, i.e., PBE-D/DZP, using the SIESTA code. ${ }^{56} \mathrm{All}$ of the atomic positions and lattice parameters were relaxed using the conjugated gradient minimization method. The theoretical solid-state structures obtained in this study were modeled departing from the one experimentally obtained for the rubicene crystal, which was indeed previously employed as a benchmark to validate the methodology. Afterwards, the transfer integral parameters $V_{\text {if }}$ were calculated for the different pairs of molecules extracted from both the $X$-ray structures and modeled crystals. $V_{\text {if }}$ calculations were carried out using the electron transfer module implemented in NWChem 6.5 package ${ }^{57}$ over each dimer and by using the UHF/cc-pVDZ level of theory.

\section{RESULTS AND DISCUSSION}

\subsection{Molecular structures}

We have first checked how the introduction of substituents in rubicene and dibenzorubicene might change the relevant dihedral angles (see figure 2), which could be related with the stacking and solid-state packing of dimers. ${ }^{10,11}$ Moreover, we have also analyzed the dibenzorubicene structure and compared it with the experimental results.10,11 Table 1 shows the calculated values (at the B3LYP/6-31+G* level) for the dihedral angles.
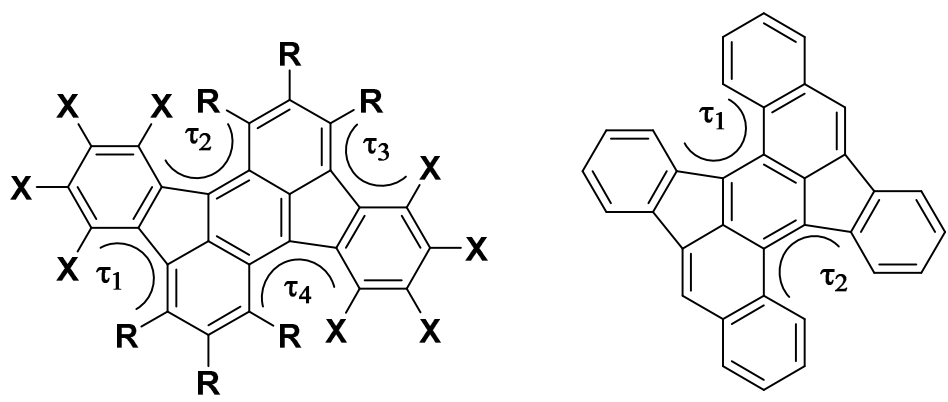

Fig. 2. Sketch of relevant dihedral angles of rubicene and its derivatives (left) and dibenzorubicene (right) 
Table 1. Dihedral angles (in degrees) of rubicene structure and its derivatives, calculated at B3LYP/6 $-31+G^{*}$ level of theory. A positive (negative) value for $\mathrm{T}$ implies a clockwise (anti-clockwise) orientation in the measurement of the angles.

$\begin{array}{lcccc}\text { Compounds } & \mathbf{T}_{1} & \mathbf{T}_{\mathbf{2}} & \mathbf{T}_{\mathbf{3}} & \mathbf{T}_{4} \\ \text { Rubicene } & 0.00 & 0.00 & 0.01 & 0.00 \\ & & & & \\ \text { 6F-Rubicene } & 0.00 & 0.00 & 0.00 & 0.00 \\ \text { 6Cl-Rubicene } & 5.18 & -10.08 & 5.16 & -10.08 \\ \text { 6Br-Rubicene } & 5.10 & -9.69 & 5.08 & -9.72 \\ \text { 6CN-Rubicene } & 3.99 & -8.74 & 3.99 & -8.73 \\ & & & & \\ \text { 8F-Rubicene } & 0.00 & 0.00 & 0.00 & 0.00 \\ \text { 8Cl-Rubicene } & -14.65 & 7.22 & 14.67 & -7.23 \\ \text { 8Br-Rubicene } & -3.52 & 28.44 & -3.52 & 28.44 \\ \text { 8CN-Rubicene } & -1.99 & 15.53 & -1.99 & 15.53 \\ & & & & \\ \text { pF-Rubicene } & 6.56 & -18.69 & 6.56 & -18.70 \\ \text { pCl-Rubicene } & 31.55 & -27.45 & 31.56 & -29.28 \\ \text { pBr-Rubicene } & 36.67 & -30.03 & 36.66 & 30.03 \\ \text { pCN-Rubicene } & 23.99 & -25.21 & 23.99 & -25.21 \\ & & & & \\ \text { Dibenzorubicene } & 17.43 & 17.44 & & \end{array}$

As we initially expected, the rubicene molecule remains planar, agreeing with the experimental structure previously published, ${ }^{10}$ in which the crystal structure shows, apparently, a planar and conjugated system. However, we have observed that the introduction of some substituents disrupts this planarity. Actually, the introduction of $\mathrm{Cl}, \mathrm{Br}$ or $\mathrm{CN}$ substituents greatly distorts the unsubstituted structure (see figure 3), independently of the number of introduced substituents (see table 1), in order to reduce the steric hindrance. In the case of fluorine atoms as substituents, some changes have been only observed for pF-rubicene, obtaining dihedral angles close to zero for the set of systems considered. With respect to the dibenzorubicene molecule, the dihedral angles between both planes are similar (around $17^{\circ}$ ) while the experimental structure shows values of $13.9^{\circ}$ and $16.2^{\circ}$, and thus losing the symmetry, due probably to packing effects. ${ }^{10}$ In fact, dibenzorubicene is known to have two different conformers, showing the most stable equal values for the dihedral angles, in agreement with our gas-phase estimates. ${ }^{10}$

a)

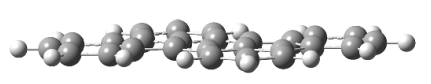

c)

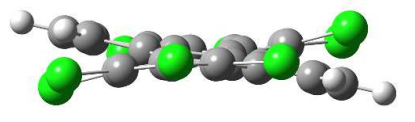

b)

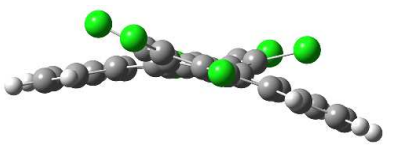

d)

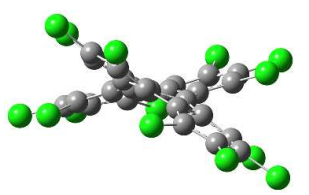

Fig. 3. Selected view of a) rubicene, b) $6 \mathrm{Cl}$-rubicene, c) $8 \mathrm{Cl}$-rubicene and d) $\mathrm{pCl}$-rubicene, respectively, clearly showing the changes in dihedral angles upon substitution.

On the other hand, we have further modelled some unknown crystal structures taking as starting point the X-ray data of rubicene, ${ }^{10}$ after carefully assessing the methodology first. Due to the large geometrical differences between rubicene and their substituted derivatives (see figure 3 and table 1), we have only tackled the 6-fluorinated

6 
derivative. Table 2 shows the correspondingly calculated lattice parameters for rubicene and its fluorinated derivatives. As we observe, no large differences between experimental and theoretical structures (in the case of rubicene) have been found, which validates the methodology employed so far. Therefore, we have correspondingly simulated the crystal structure of 6F-rubicene (see figure 4) whose arrangements are expected to be similar to rubicene. Figure 4 displays the 3D view of rubicene and 6F-rubicene structures, both showing a herringbone disposition although $6 \mathrm{~F}$-rubicene also features some T-shaped stacking. These results resemble those reported before for pentacene crystals, where a change in the crystal configuration is observed on going from pentacene to perfluorinated pentacene. ${ }^{58-60}$ Interestingly, a more pronunciated cofacial stacking (see figure 4) is obtained after fluorination which, in turn, may improve the electronic coupling (vide infra). A similar behavior has been previously observed in other systems such as diphenyltetrazine derivatives ${ }^{14}$ or dibenzodifuranione-based oligo( $p$ phenylenevinylene) (BDOPV) derivatives. ${ }^{6}$

a)
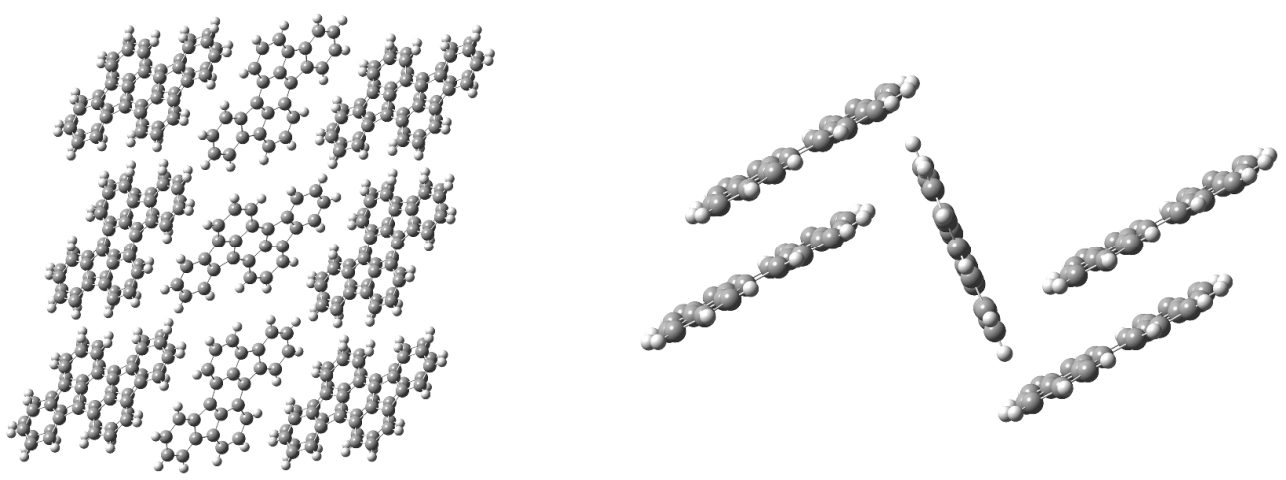

b)
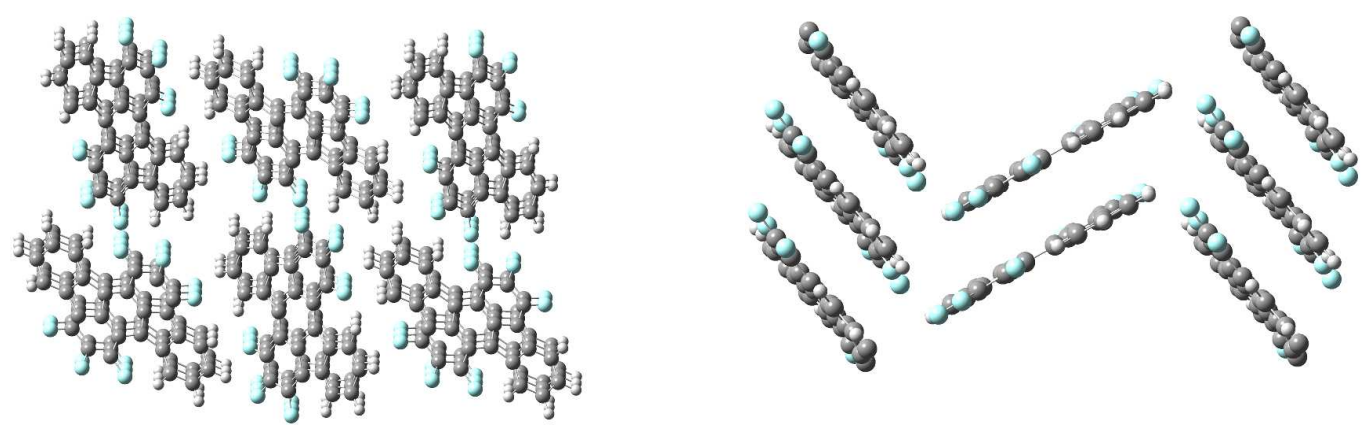

Figure 4. Molecular arrangements from the X-ray crystal structure of rubicene (top) and simulated crystal structure of 6F-rubicene (bottom). 
Table 2. Crystallographic lattice parameters ( $a, b, c, a, \beta$ and $y$ ) for the studied compounds.

\begin{tabular}{cccc} 
& \multicolumn{2}{c}{ Rubicene } & 6F-Rubicene \\
Lattice parameters & Expa & Theory & Theory \\
$\mathrm{a} / \AA$ & 16.29 & 16.59 & 19.10 \\
$\mathrm{~b} / \AA$ & 5.14 & 5.33 & 4.58 \\
$\mathrm{c} / \AA$ & 19.06 & 19.63 & 20.05 \\
$\mathrm{a} /$ degrees & 90.00 & 90.00 & 91.63 \\
$\beta /$ degrees & 97.02 & 96.36 & 91.70 \\
$\mathrm{Y} /$ degrees & 90.00 & 90.00 & 86.73 \\
\hline \multicolumn{2}{l}{ a Values taken from Ref. [10] }
\end{tabular}

\subsection{Charge Injection.}

The charge injection relies on the energy difference between the energy of the frontier orbitals (HOMO and LUMO) and the work function $\left(\Phi_{\mathrm{m}}\right)$ of the metal injecting the charge (hole or electron) into the organic layers; and on the ionization potential $(I P) /$ electron affinity $(E A)$, depending on the nature of the semiconductor ( $p$ - or $n$-type semiconductor), corrected by the interfacial dipoles. ${ }^{23,38}$ The dipoles derived from either partial charge-transfer metalsemiconductor, the reduction of the metal work function by the organic layer, or the occupation of the metal-induced density of states in the gap of the organic material, have not been taken into account. ${ }^{62,63}$ Although a complete description of the metal/organic interface should account for those specific interactions, the comparison between the free metal work function and the (gas-phase) HOMO/LUMO levels will not give exact information but, nonetheless, give us a qualitative guide for the electron/hole barrier injection, and thus to establish trends within a set of related compounds. ${ }^{38}$ In that sense, we have checked the omhic contact between semiconductor and electrode, from the expression $\mid$ Еномо/цимо - $\Phi_{\mathrm{m}} \mid \leq 0.3 \mathrm{eV} .{ }^{42}$

Table 3 shows the energy values for HOMO and LUMO orbitals and the corresponding energy difference

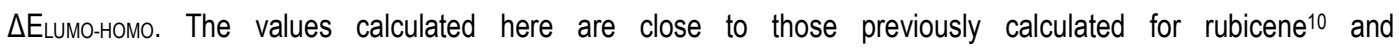
dibenzorubicene, ${ }^{11}$ which are between $-2.54 \mathrm{eV}$ and -2.68 (for LUMO orbital) and $-5.29 \mathrm{eV}$ and -5.67 (for HOMO orbital), respectively. The values of the rest of compounds differ from those obtained before for other state-of-the-art molecules such as tetracene ( -2.09 and $-4.87 \mathrm{eV})$, pentacene $(-2.40$ and $-4.61 \mathrm{eV})$ or rubrene $(-2.09$ and $-4.69 \mathrm{eV})$, calculated at the B3LYP/6-31G* level, and other fused-PAH (such as corannulene, circumtrindene, hemifullerene or circobiphenyl) whose LUMO energy (calculated at B3LYP/6-31G* level) are lower than the values calculated in this work. ${ }^{64}$ Moreover, the halogenation exhibits the well-known effect of decreasing the energy of the orbitals, normally, leading to a more favored charge injection. In that sense, as we stated before, a low LUMO energy facilitates the electron injection, and could also help to enhance the environmental stability of the material, although there is not still a general guideline for prediction of the air stability for $n$-type semiconductors. On the other hand, a high HOMO energy eases the hole injection, for which a good ohmic contact is predicted for almost all systems, except for $\mathrm{pCN}$ Rubicene structure, with a large variety of metal oxides such as $\mathrm{WO}_{3}\left(\Phi_{\mathrm{m}}=-6.8 \mathrm{eV}\right), \mathrm{MoO}_{3}\left(\Phi_{\mathrm{m}}=-6.8 \mathrm{eV}\right), \mathrm{NiO}\left(\Phi_{\mathrm{m}}\right.$ $=-6.3), \mathrm{CuO}\left(\Phi_{\mathrm{m}}=-5.9 \mathrm{eV}\right)$, and $\mathrm{MoO}_{2}\left(\Phi_{\mathrm{m}}=-5.9 \mathrm{eV}\right) ; 65,66$ while the most useful electrodes, such as $\mathrm{Ca}\left(\Phi_{\mathrm{m}}=-2.9\right.$ $\mathrm{eV}), \mathrm{Mg}\left(\Phi_{\mathrm{m}}=-3.7 \mathrm{eV}\right)$, and $\mathrm{Al}\left(\Phi_{\mathrm{m}}=-4.3 \mathrm{eV}\right)^{37}$ could be used to produce ohmic electron-injection contact with the majority of the studied molecules. Again, pCN-Rubicene does not produce ohmic contact with any electrodes, and its use is thus not recommended. 
Indium tin oxide (ITO) $\left(\Phi_{\mathrm{m}}=-4.7 \mathrm{eV}\right)^{36}$ and gold electrodes $(\mathrm{Au})\left(\Phi_{\mathrm{m}}=-5.1 \mathrm{eV}\right)^{37,67}$ are usually employed as electrodes for ambipolar semiconductors, but their $\Phi_{m}$ values are not low enough to ensure ohmic hole-injection contact or electron injection with the majority of the herein studied molecules. This drawback can be overcome by employing electrodes with lower $\Phi_{\mathrm{m}}$ values such as chlorinated ITO (CIIITO) $\left(\Phi_{\mathrm{m}}=-6.1 \mathrm{eV}\right)$ or gold electrodes with self-assembled monolayers of alkanethiols or polythiols $\left(\Phi_{m}=-5.5--5.8 \mathrm{eV}\right)^{68}$ which may make easier the hole injection into the semiconductor, ${ }^{69}$ but it conversely could hinder electron injection due to the increase of the $\Phi_{m}-$ Euumo gap. Hence, molecules with narrow band gaps are more suited to be employed as ambipolar semiconductors

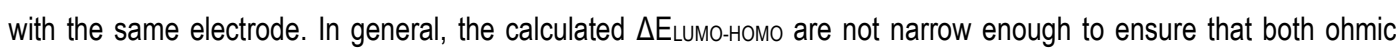
hole- and electron injection contacts are produced with the same type of electrode. Only in the case of cyanated derivatives is possible to predict an ambipolar character. However, as we commented above, the $\mathrm{pCN}$-rubicene compound has very high orbital energy values, which is expected to preclude an efficient charge injection.

Observing the energy of the LUMO orbitals, and contrary to other studied structures, ${ }^{19,31}$ the introduction of halogenated or cyanated substituents does not produce changes in the orbital energy values, in order to improve (or increase) the $n$-type semiconductor character of the derivative systems. In these structures, the introduction of halogenated or cyanated substituents yields a stabilization effect of the electronic structure, increasing the $p$-type semiconductor character of the systems. In that sense, we have observed that the introduction of halogenated or cyanated groups yields a stabilization of the LUMO orbital, with a decrease in the LUMO energy. This effect is more pronounced in the case of cyanated-rubicene derivatives, which could be due to changes in the shape of LUMO and $(L+1)$ UMO orbitals (see Figure $1 S$ in the Supporting Information). Note that the orbitals are not totally delocalized over all the molecules, as opposed to the rest of the studied molecules, which could generate a stabilization of the LUMO orbitals.

Table 3. Energy values for HOMO and LUMO orbitals, and $\triangle \mathrm{E}_{\text {Lumo-HOMO }}(\mathrm{eV})$ for rubicene and its derivatives, as calculated at B3LYP/6-31+G* level

\begin{tabular}{lccc} 
Compounds & HOMO (eV) & LUMO (eV) & $\Delta$ ELumo- номо (eV) \\
\hline Rubicene & -5.559 & -2.847 & 2.712 \\
& & -3.420 & 2.696 \\
6F-Rubicene & -6.116 & -3.522 & 2.557 \\
6Cl-Rubicene & -6.079 & -3.510 & 2.521 \\
6Br-Rubicene & -6.031 & -197 \\
6CN-Rubicene & -7.108 & -4.911 & 2.197 \\
& & & \\
8F-Rubicene & -6.236 & -3.545 & 2.690 \\
8Cl-Rubicene & -6.200 & -3.552 & 2.648 \\
8Br-Rubicene & -6.139 & -3.522 & 2.616 \\
8CN-Rubicene & -7.536 & -4.964 & 2.572 \\
& & & \\
pF-Rubicene & -6.696 & -4.102 & 2.593 \\
pCl-Rubicene & -6.464 & -4.032 & 2.432 \\
pBr-Rubicene & -6.326 & -3.935 & 2.391 \\
pCN-Rubicene & -8.652 & -6.364 & 2.288 \\
& & & \\
Dibenzorubicene & -5.608 & -2.612 & 2.995
\end{tabular}

Table 4 shows the vertical (VEA and VIP), adiabatic (AEA and AIP) and the quasiparticle energy gap (QEG) values estimated for rubicene (and its substituted derivatives) as well as for dibenzorubicene. As we know, to ensure the air stability of the material, its EA must be ranged between 3.4 and $4.0 \mathrm{eV}$, condition that it is only satisfied by all per-substituted derivatives, except $\mathrm{pCN}$-rubicene. On the other hand, the IP must be low enough to 
allow an easy hole injection into the HOMO orbital, with the lowest value obtained for cyanated derivatives. With respect to the QEG (the gap between these two values), the calculations show that the narrower gap corresponds to per-substituted rubicene (with the exception of pF-Rubicene) and the $6 \mathrm{CN}$-derivative, which could indicate that these compounds may undergo an ambipolar behavior.

Table 4. Calculated electron affinity (AEA and VEA), ionization potential (AIP and VIP), quasiparticule energy gap (QEG) and reorganization energy $\left(\lambda_{i}^{+}\right.$and $\left.\lambda_{i}^{-}\right)$values for rubicene and its derivatives, as calculated at B3LYP/6-31+G ${ }^{*}$ level.

$\begin{array}{llllllll}\text { Compounds } & \text { AIP }(\mathrm{eV}) & \text { VIP }(\mathrm{eV}) & \text { AEA }(\mathrm{eV}) & \text { VEA }(\mathrm{eV}) & \text { QEG } / \mathrm{eV} & \lambda_{i}^{+}(\mathrm{eV}) & \lambda_{i}^{-}(\mathrm{eV}) \\ \text { Rubicene } & 6.760 & 6.831 & 1.681 & 1.581 & 5.079 & 0.146 & 0.198 \\ & & & & & & & \\ \text { 6F-Rubicene } & 7.294 & 7.383 & 2.269 & 2.140 & 5.025 & 0.184 & 0.256 \\ \text { 6Cl-Rubicene } & 7.157 & 7.215 & 2.458 & 2.353 & 4.699 & 0.193 & 0.207 \\ \text { 6Br-Rubicene } & 7.068 & 7.160 & 2.485 & 2.392 & 4.583 & 0.188 & 0.183 \\ \text { 6CN-Rubicene } & 8.164 & 8.269 & 3.837 & 3.776 & 4.327 & 0.217 & 0.122 \\ & & & & & & & \\ \text { 8F-Rubicene } & 7.420 & 7.509 & 2.395 & 2.268 & 5.025 & 0.179 & 0.253 \\ \text { 8Cl-Rubicene } & 7.268 & 7.340 & 2.514 & 2.392 & 4.754 & 0.147 & 0.243 \\ \text { 8Br-Rubicene } & 7.155 & 7.227 & 2.528 & 2.408 & 4.627 & 0.146 & 0.240 \\ \text { 8CN-Rubicene } & 8.612 & 8.661 & 3.971 & 3.858 & 4.641 & 0.098 & 0.225 \\ & & & & & & & \\ \text { pF-Rubicene } & 7.846 & 7.954 & 2.976 & 2.823 & 4.870 & 0.219 & 0.305 \\ \text { pCl-Rubicene } & 7.439 & 7.521 & 3.083 & 2.955 & 4.356 & 0.166 & 0.254 \\ \text { pBr-Rubicene } & 7.241 & 7.316 & 3.053 & 2.930 & 4.188 & 0.147 & 0.235 \\ \text { pCN-Rubicene } & 9.607 & 9.663 & 5.421 & 5.333 & 4.186 & 0.114 & 0.172 \\ & & & & & & & \\ \text { Dibenzorubicene } & 6.671 & 6.765 & 1.561 & 1.475 & 5.110 & 0.196 & 0.172\end{array}$

\section{3. $\underline{\text { Charge transport }}$}

The calculated $\lambda_{\mathrm{i}}$ values are also shown in table 4 . All the values are comprised between 0.098 to $0.219 \mathrm{eV}$ for holes and from 0.122 to $0.305 \mathrm{eV}$ for electrons, obtaining the lowest (highest) values for hole injection for $\mathrm{pCN}$ rubicene (pF-rubicene), respectively; while the lowest (highest) values for electron injection have been obtained for $6 \mathrm{CN}$-rubicene (pF-rubicene), respectively. This behavior, i.e. the increase of $\lambda_{i}$ values with the introduction of fluorinated substituents, has been previously observed in other acenes such as anthracene, tetracenes, pentacene, pyrenes or cincumacenes ${ }^{70}$ and some tri-isopropilsililpentacene derivatives..$^{71}$ Note that the halogenation does not generally reduce the $\lambda_{i}$ values obtained for rubicene, unless for hole transport in some derivative structures (i. e., for $8 \mathrm{CN}$-rubicene derivative). In spite of it, these calculated $\lambda_{i}$ are in the range of other acene derivatives typically used as n-type semiconductor such as perfluorpentacene $(0.24 \mathrm{eV})^{72}$ and some diimides $(0.24-0.35 \mathrm{eV})^{73}$ calculated at the B3LYP/6-31++G* level, and much lower than for some trifluoromethylated PAH $(0.35-0.55 \mathrm{eV})^{74}$ calculated at the B3LYP/6-1G** level; and similar to other organic compounds used as p-type semiconductors such as halogenated tri-isopropilpentacene derivatives $(0.134-0.168 \mathrm{eV})^{71}$ calculated at the B3LYP/6-311++G*//B3LYP/6$31 \mathrm{G}^{* *}$ level of theory, and lower than some trifluoromethylated PAH $(0.30-0.50 \mathrm{eV})^{74}$ calculated at the B3LYP/6$1 G^{* *}$.

Table 5 shows the calculated values of $V_{i j}$, the charge transport rates $\left(k_{C T}\right)$ and the associated mobilities $(\mu)$. Incorporating the calculated values of reorganization energy and electronic coupling to the corresponding equations, we have also estimated the charge transport rate (eq. 1) and the mobility (eq. 8) for both charge carriers (hole and electron). As we expected, the dimer in coplanar dispositions, i. e. dimer 1, 7 and 1 for the (experimental or simulated) crystal of rubicene, dibenzorubicene and 6F-rubicene, respectively (see figures $5-7$ ), yields the lowest distance between center-to-center dimers. Logically, these lowest distances are correlated with the highest electron 
coupling, and them, with the most favorable charge transport rates for hole charge carriers. As we observed above, and unlikely expected, the introduction of halogenated substituents increases the p-type character of the studied structures. In that sense, for the pristine rubicene, the hole character is 9 -fold factor higher than electron character, which increase until 30-fold factor when some hydrogen atoms are substituted for fluorine atoms.

Table 5. Calculated $V_{i j}(\mathrm{meV})$ values for Rubicene, its $6 F$-derivative and Dibenzorubicene, along with the center-tocenter distance between dimers $(r, \AA)$ and the estimated values for $k_{c T}\left(\mathrm{~s}^{-1}\right), \mu\left(\mathrm{V}^{-1} \mathrm{~cm}^{2} \mathrm{~s}^{-1}\right)$ and the ratio $\mu^{+} / \mu-$

\begin{tabular}{|c|c|c|c|c|c|c|c|c|c|}
\hline & \multirow[b]{2}{*}{ Dimer } & \multirow[b]{2}{*}{$r / \AA$} & \multicolumn{3}{|c|}{ Hole } & \multicolumn{3}{|c|}{ Electron } & \multirow[b]{2}{*}{$\mu^{+} / \mu$} \\
\hline & & & $V_{\text {if }} / \mathrm{meV}$ & $k_{C T} / s^{-1}$ & $\begin{array}{c}\mu / V^{-1} \mathrm{~cm}^{2} \\
\mathrm{~s}^{-1}\end{array}$ & $V_{\text {if }} / \mathrm{meV}$ & $k_{C T} / s^{-1}$ & $\begin{array}{c}\mu / V^{-1} \mathrm{~cm}^{2} \\
\mathrm{~s}^{-1}\end{array}$ & \\
\hline \multirow{3}{*}{ Rubicene } & 1 & 5.14 & 177.8 & $3.07 \times 10^{14}$ & \multirow{3}{*}{5.2} & 67.0 & $2.67 \times 10^{13}$ & \multirow{3}{*}{0.6} & \multirow{3}{*}{9.1} \\
\hline & 2 & 8.81 & 22.9 & $1.79 \times 10^{11}$ & & 8.0 & $3.26 \times 10^{11}$ & & \\
\hline & 3 & 8.81 & 22.9 & $1.79 \times 10^{11}$ & & 7.7 & $3.26 \times 10^{11}$ & & \\
\hline \multirow{8}{*}{$\begin{array}{c}\text { Dibenzo } \\
\text { Rubicene }\end{array}$} & 1 & 11.15 & 51.5 & $2.26 \times 10^{13}$ & \multirow{8}{*}{2.9} & 0.4 & $9.74 \times 10^{8}$ & \multirow{8}{*}{0.6} & \multirow{8}{*}{4.6} \\
\hline & 2 & 10.95 & 13.3 & $1.51 \times 10^{12}$ & & 22.9 & $3.67 \times 10^{12}$ & & \\
\hline & 3 & 11.85 & 6.7 & $3.85 \times 10^{11}$ & & 44.3 & $1.48 \times 10^{13}$ & & \\
\hline & 4 & 15.12 & 12.1 & $1.24 \times 10^{13}$ & & 33.9 & $8.70 \times 10^{12}$ & & \\
\hline & 5 & 11.85 & 6.2 & $3.32 \times 10^{11}$ & & 10.6 & $8.53 \times 10^{11}$ & & \\
\hline & 6 & 12.40 & 5.2 & $2.32 \times 10^{11}$ & & 0.2 & $4.35 \times 10^{8}$ & & \\
\hline & 7 & 3.92 & 190.5 & $3.09 \times 10^{14}$ & & 66.7 & $3.37 \times 10^{13}$ & & \\
\hline & 8 & 10.95 & 12.2 & $1.26 \times 10^{12}$ & & 28.8 & $6.28 \times 10^{12}$ & & \\
\hline \multirow{6}{*}{ 6F-Rubicene } & 1 & 4.55 & 229.3 & $4.48 \times 10^{14}$ & \multirow{6}{*}{5.8} & 44.6 & $1.50 \times 10^{13}$ & \multirow{6}{*}{0.2} & \multirow{6}{*}{30.5} \\
\hline & 2 & 11.72 & 1.6 & $2.29 \times 10^{10}$ & & 4.7 & $1.70 \times 10^{11}$ & & \\
\hline & 3 & 10.80 & 55.9 & $2.66 \times 10^{13}$ & & 12.7 & $1.23 \times 10^{12}$ & & \\
\hline & 4 & 11.25 & 0.1 & $6.30 \times 10^{07}$ & & 5.4 & $2.22 \times 10^{11}$ & & \\
\hline & 5 & 11.19 & 0.8 & $4.88 \times 10^{09}$ & & 1.1 & $8.46 \times 10^{09}$ & & \\
\hline & 6 & 9.68 & 3.7 & $1.18 \times 10^{11}$ & & 6.8 & $3.54 \times 10^{11}$ & & \\
\hline
\end{tabular}




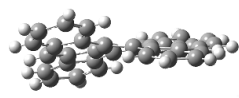

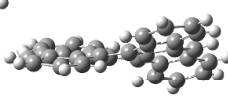

DIMER 1

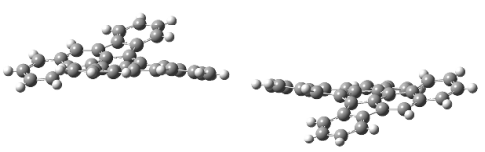

DIMER 4

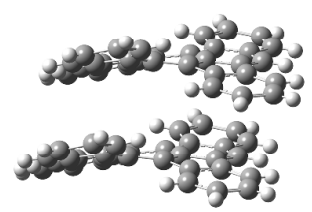

DIMER 7

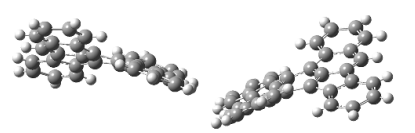

DIMER 2

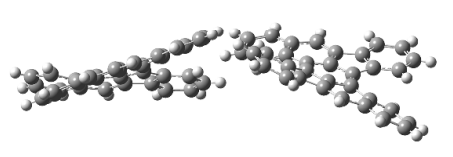

DIMER 5

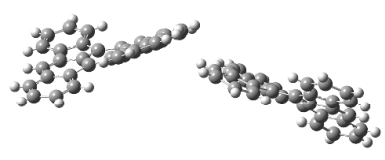

DIMER 8

Figure 6. Sketch of the different dimers extracted from the experimental (X-Ray) data for dibenzorubicene
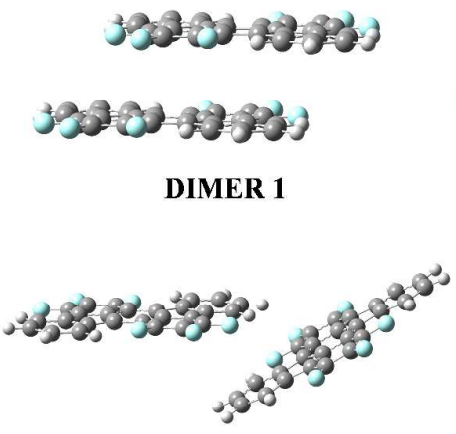

DIMER 4

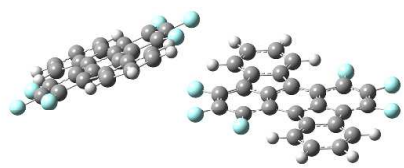

DIMER 2

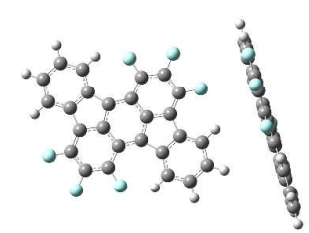

DIMER 5

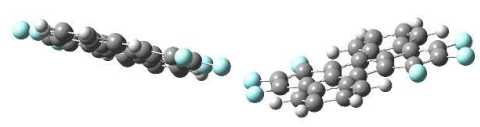

DIMER 3

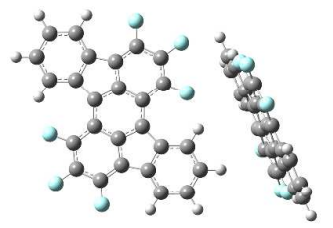

DIMER 6

Figure 7. Sketch of the different dimers extracted from the simulated crystal data for 6F-rubicene.

\section{CONCLUSION}

In this work, we have studied the influence of partial or total peripherical substitution of hydrogen atoms by halogen atoms and cyano grups in rubicene. This study focused first on the structural changes of isolated molecules upon substitution, and the subsequent implications for the solid-state packing of the samples.

We have systematically compared some selected dihedral angles, observing that the introduction of some substituents disrupts the planarity of rubicene, in order to reduce the steric hindrance. The crystallographic parameters of rubicene have been accurately reproduced by our calculations, with the purpose to simulate the solidstate structure of $6 \mathrm{~F}$-rubicene to disclose then structure-property relationships.

For the study of the semiconductor behavior, and in the case of charge injection properties, we have compared the energy of the frontier (HOMO and LUMO) orbitals with the most commonly used electrodes, observing that only an ohmic contact is possible when some metal oxides are employed. On the other hand, the quasiparticle energy gap values indicate that the per-substituted compounds and $6 \mathrm{CN}$-rubicene could act as ambipolar semiconductors. However, unexpectedly, the introduction of halogenated or cyanated substituents increases the $p$ - 
type semiconductor character, as deduced from energy orbital values and from calculated (reorganization energy and electronic coupling) and simulated (charge transport rate and mobility) parameters. In that sense, the introduction of halogenated substituents yields an increase in the hole motilities by a 3-fold factor from the initial (rubicene) structure to the halogenated (6F-rubicene) one. For the case of dibenzorubicene, where multiple paths for charge-carries hopping are found upon crystallization, we found the lowest ratio between hole and electron mobilities, together with reasonably high individual values.

\section{ACKNOWLEDGEMENTS}

This work is supported by the "Ministerio de Economía y Competitividad"' of Spain and the "European Regional Development Fund" through project CTQ2014-55073-P. We gratefully acknowledge Supercomputing Service of Castilla-La Mancha University for allocation of computational resources. Mónica Moral Muñoz thanks to the E2TP-CYTEMA-SANTANDER program for their financial support.

\section{REFERENCES}

[1] Goetz, S. M.; Erlen, C. M.; Grothe, H.; Wolf, B.; Lugli, P.; Scarpa, G. Organic Field-Effect Transistors for Biosensing Applications. Org. Electron., 2009, 10, 573 - 580.

[2] de Leeuw, D. M.; Cantatore, E. Organic Electronic: Materials, Technology and Circuit Design Developments Enabling New Applications. Mater. Sci. Semicond. Process, 2008, 11, 199-204.

[3] Bown, M.; Dunn, C. J.; Forsyth, C. M.; Kemppinene, P.; Singh, T. B.; Skidmore, M. A.; Winzenberg, K. N. First Synthesis of Diindeno[1,2-g':1'.2'-s']rubicene Derivatives and Their Evaluation as Semiconductors. Aust. J. Chem., 2012, 65, 145-152.

[4] Anthony, J. E. The Large Acenes: Versatile Organic Semiconductors. Angew. Chem. Int. Ed., 2008, 47, 452-483.

[5] Anthony, J. E.; Facchetti, A.; Heeney, M.; Marder, S. R.; Zhan, X. N-Type Organic Semiconductors in Organic Electronics. Adv. Mater., 2010, 22, 3876-3892.

[6] Yamane, Y.; Sugawara, K.; Nakamura, N.; Hayase, S.; Nokami, T.; Itoh, T. Development of n-Type Semiconductors Based on Cyclopentane- or Cyclohexene-Fused [ $\left.\mathrm{C}_{60}\right]$-Fullerene Derivatives. J. Org. Chem., 2015, 80, 4638 - 4649 .

[7] Li, X.; Wang, X.; Zhang, L.; Lee, S.; Dai, H. Chemically Derived, Ultrasmooth Graphene Nanoribbons Semiconductors. Science, 2008, 319, 1229-1232.

[8] Ye, Y.; Gan, L.; Dai, L.; Meng, H.; Wei, F.; Dai, Y.; Shi, Z.; Yu, B.; Guo, X.; Qin, G. Multicolor Graphene Nanoribbons/Semiconductor Nanowire Heterojunction Light-emitting diodes. J. Mater. Chem., 2011, 21, 11760-11763.

[9] Sancho-García, J. C.; Moral, M.; Pérez-Jiménez, A. J. Effect of Cyclic Topology on Charge-Transfer Properties of Organic Semiconductors: The Case of Cycloparaphenylene Molecules. J. Phys. Chem. C, 2016, 120, 9104-9111.

[10] Lee, H.; Zhang, Y.; Zhang, L.; Mirabito, T.; Burnett, E. K.; Trahan, S.; Mohebbi, A. R.;. Mannsfeld, S. C. B; Wudl, F.; Briseno, A. L. Rubicene. A Molecular Fragment of $\mathrm{C}_{70}$ for Use in Organic Field-Effect Transistors. J. Mater. Chem. C., 2014, 2, 3361-3366. 
[11] Gu, X.; Xu, X.; Li, H.; Liu, Z.; Miao, Q. Synthesis, Molecular Packing, and Thin Film Transistors of Dibenzo[a,m]rubicenes. J. Am. Chem. Soc., 2015, 137, 16203-16208.

[12] Marcus, R.A. Electron Transfer Reaction in Chemistry. Theory and Experiment. Rev. Mod. Phys. 1993, 65, 599-610.

[13] Barbara, P.F.; Meyer, T.J.; Ratner, M.A. Contemporary Issues in Electron Transfer Research. J. Phys. Chem., 1996, 100, 13148-13168.

[14] Moral, M; Garcia, G.; Garzón, A.; Granadino-Roldán, J.M.; Fox, M. A.; Yufit, D. A.; Peñas, A.; Melguizo, M.; Fernández-Gómez, M. Electronic Structure and Charge Transport Properties of a Series of 3,6-(Diphenyl)s-tetrazine Derivatives: Are They Suitable Candidates for Molecular Electronics? J. Phys. Chem. C., 2014, 118, 26427-26439.

[15] Moral, M; Garzón, A.; Oliver, Y.; Muccioli, L.; Sancho-Garcia, J.C.; Granadino-Roldán, J.M.; FernándezGómez, M. Bis(arylene-ethynylene)-s-tetrazines: A Promising Family of $n$-Type Organic Semiconductors. J. Phys. Chem. C. 2015, 119, 18945-18955.

[16] Stehr, V.; Fink, R. F.; Tafipolski, M.; Deibel, C.; Engels, B. Comparison of Different Rate Constant Expressions for the Prediction of Charge and Energy Transport in Oligoacenes. WIREs Comput. Mol. Sci., 2016, doi: 10.1002/wcms. 1273.

[17] Olivier, Y.; Lemaur, V.; Brédas, J. L.; Cornil, J. Charge Hopping in Organic Semiconductors: Influence of Molecular Parameters on Macroscopic Mobilities in Model One-Dimensional Stacks. J. Phys. Chem. A, 2006, 110, 6356-6364.

[18] Burquel, A.; Lemaur, V.; Beljonne, D.; Lazzaroni, R.; Cornil, J. Pathways for Photoinduced Charge Separation and Recombination at Donor-Acceptor Heterojunctions: The Case of OligophenylenevinylenePerylene Bisimide Complexes. J. Phys. Chem. A, 2006, 110, 3447-3453.

[19] Chen, H. Y.; Chao, I. Effect of Perfluorination on The Charge-Transport Properties of Semiconductors: Density Functional Theory Study of Perfluorinated Pentacene and Sexithiophene. Chem. Phys. Lett. 2005, 401, 539-545.

[20] Troisi, A. Charge Transport in High Mobility Molecular Semiconductors: Classical Model and New Theories. Chem. Soc. Rev., 2011, 40, 2347-2358.

[21] Brédas, J.L.; Beljonne, D.; Coropceanu, V.; Cornil, J. Charge-Transfer and Energy-Transfer Process in חConjugated Oligomers and Polymers: A Molecular Picture. Chem. Rev. 2004, 104, 4971-5004.

[22] Coropceanu, V.; André, J.M.; Malagoli, M.; Brédas, J.L. The Role of Vibronic Interactions on Intramolecular and Intermolecular Electron Transfer in $\pi$-Conjugated Oligomers. Theor. Chem. Acc. 2003, 110, 59-69.

[23] McMahon, D. P.; Troisi, A. Evaluation of the External Reorganization Energy of Polyacenes. J. Phys. Chem. Lett., 2010, 1, 941-946.

[24] Norton, J.E.; Brédas, J. L. Polarization Energies in Oligoacene Semiconductor Crystals. J. Am. Chem. Soc. 2008, 130, 12377-12384.

[25] Martinelli, N. G.; Savini, M.; Muccioli, L.; Olivier, Y.; Castet, F.; Zannoni, C.; Beljonne, D.; Cornil, J. Modeling Polymer Dielectric/Pentacene Interfaces: On the Role of Electrostatic Energy Disorder on Charge Carrier Mobility. Adv. Funct. Mater., 2009, 19, 3254-3261.

[26] Lemaur, V.; Steel, M.; Beljonne, D.; Brédas, J. L.; Cornil, J. Photoinduced Charge Generation and Recombination Dynamics in Model Donor/Acceptor Pairs for Organic Solar Cell Applications: A Full Quantum-Chemical Treatment. J. Am. Chem. Soc. 2005, 127, 6077-6086.

14 
[27] Nelsen, S. F.; Blackstock, S. C.; Kim, Y. Estimation of Inner Shell Marcus Terms for Amino Nitrogen Compounds by Molecular Orbital Calculations. J. Am. Chem. Soc., 1987, 109, 677-682.

[28] Nelsen, S. F.; Yunta, M. J. R. Estimation of Marcus $\lambda$ for $p$-Phenylenediamines from The Optical Spectrum of a Dimeric Derivative. J. Phys. Org. Chem., 1994, 7, 55-62.

[29] Wang, L.; Nan, G.; Yang, X.; Peng, Q.; Li, Q.; Shuai, Z. Computational methods for design of organic materials with high charge mobility. Chem. Soc. Rev. 2010, 39, $423-434$.

[30] Coropceanu, V.; Cornil, J.; da Silva Filho, D.A.; Olivier, Y.; Silvey, R.; Brédas. J.L. Charge Transport in Organic Semiconductors. Chem. Rev., 2007, 107, 926-952.

[31] Moral, M.; García, G.; Garzón, A.; Granadino-Roldán, J. M.; Fernández-Gómez, M. DFT Study of the Effect of Fluorine Atoms on The Crystal Structure and Semiconducting Properties of Poly(arylene-ehynylene) Derivatives. J. Chem. Phys., 2016, 144, 154902.

[32] Wang, L.; Nan, G.; Yang, X.; Peng, Q.; Li, Q.; Shuai, Z. Computational Methods for Design of Organic Materials with High Charge Mobility. Chem. Soc. Rev., 2010, 39, 423-434.

[33] Cheung, D. L.; Troisi, A. Modelling Charge Transport in Organic Semiconductors: From Quantum Dynamics to Soft Matter. Phys. Chem. Chem. Phys., 2008, 10, 5941-5952.

[34] Newton, M. D. Quantum Chemical Probes of Electron-Transfer Kinetics: The Nature of Donor-Acceptor Interactions. Chem. Rev., 1991, 91, 767-792.

[35] Farazdel, A.; Dupuis, A.; Clementi, E.; Aviram, A. Electric-Field Induced Intramolecular Electron Transfer in Spiro.pi.-electron Systems and Their Suitability as Molecular Electronic Devices. A Theoretical Study. J. Am. Chem. Soc., 1990, 112, 4206-4214.

[36] Sun, S. S.; Dalton, L. R.; Introduction to Organic Electronic and Optoelectronic Materials and Devices; CRC Press: Taylor \& Francis Group, New York, 2005.

[37] Michaelson, The Work Function of the Elements and its Periodicity. J. Appl. Phys., 1977, 48, 4729-4733.

[38] Körzdörfer, T.; Parrish, R. M.; Sears, J. S.; Sherrill, C. D.; Brédas, J. L. On the Relationship between BondLength Aleternation and Many-Electron Self-Interaction Error. J. Chem. Phys., 2012, 137, 124305.

[39] Anthopoulos, T. D.; Anyfantis, G. C.; Papavassiliou, G. C.; de Leeuw, D. M. Air-Stable Ambipolar Organic Transistors. Appl. Phys. Lett., 2007, 90, 122105.

[40] Zhan, X.; Facchetti, A.; Barlow, S.; Marks, T. J.; Ratner, M. A.; Wasielewski, M. R.; Marder, S. R. Rylene and Related Diiides for Organic Electronics. Adv. Mater., 2011, 23, 268-284.

[41] Sancho-Garcia; J. C. Application of Double-Hybrid Density Functionals to Charge Transfer in N-substituted Pentacenequinones. J. Chem. Phys. 2012, 136, 174703.

[42] Newman, C. R.; Frisbie, C. D.; da Silva Filho, D. A.; Brédas, J. L.; Ewbank, P. C.; Mann, R. K. Introduction to Organic Thin Film Transistors and Desing of n-Channel Organic Electronic. Chem. Mater. 2004, 16, 4436-4451.

[43] Frisch, M. J.; Trucks, G. W.; Schlegel, H. B.; Scuseria, G. E.; Robb, M. A.; Cheeseman, J. R.; Scalmani, G.; Barone, V.; Mennucci, B.; Petersson, G.A.; et al. Gaussian 09, revision D.01; Gaussian Inc.: Wallingford, CT, 2009.

[44] Becke, A. D. Density-Functional Termochemistry. III. The Role of Exact Exchange. J. Chem. Phys. 1993, $98,5648-5652$.

[45] Lee, C.; Yang, W.; Parr, R. G. Development of the Coll-Salvetti Correlation-Energy Formula into a Functional of the Electron Density. Phys. Rev. B. 1988, 37, 785-789. 
[46] Hung, Y. C.; Jiang, J. C.; Chao, C. Y.; Su, W. F.; Lin, S. T. Theoretical Study on the Correlation between Band Gap, Bandwidth, and Oscillator Strenght in Fluorene-Based Donor-Acceptor Conjugated Copolymers. J. Phys. Chem. B., 2009, 113, 8268-8277.

[47] Lin, B. C.; Cheng, C. P.; Lao, Z. P. M. Reorganization Energy in the Transports of Holes and Electrons in Organic Amines in Organic Electroluminiscence Studied by Density Functional Theory. J. Phys. Chem. A, 2003, 107, 5241-5251.

[48] Randic, M. Aromaticity of Polycyclic Conjugated Hydrocarbons. Chem. Rev., 2003, 103, 3449-3606.

[49] Coropceanu, V.; Malagoli, M.; da Silva Filho, D. A.; Gruhn, N. E.; Bill, T. G.; Brédas, J. L. Hole- and Electron-Vibrational Coupling in Oligoacene Crystals: Intramoleuclar Contributions. Phys. Rev. Lett., 2002, $89,275503-275507$.

[50] Zhan, C. G.; Nichols, J. A.; Dixon, D. A. Ionization Potential, Electron Affinity, Electronegativity, Hardness, and Electron Excitation Energy: Molecular Properties from Density Functional Theory. J. Phys. Chem. A., 2003, 107, 4184-4195.

[51] Rienstra-Kiracofe, J. C.; Tschumper, G. S.; Schaefer III, H. F.; Nandi, S.; Ellison, G. B. Atomic and Molecular Electron Affinities: Photoelectron Experiments and Theoretical Computations. Chem. Rev., 2002, 102, 231-282.

[52] Rienstra-Kiracofe, J. C.; Barden, C. J.; Brown, S. T.; Schaefer III, H. F. Electron Affinites of Polycyclic Aromatic Hydrocarbons. J. Phys. Chem. A., 2001, 105, 524-528.

[53] Muscat, J.; Wander, A.; Harrison, N. M. On the Prediction of Band Gaps from Hybrid Functional Theory. Chem. Phys. Lett., 2001, 342, 397-401.

[54] Perdew, J. P.; Burke, K.; Ernzerhof, M. Generalized Gradient Approximation Made Simple. Phys. Rev. Lett., 1996, 77, 3865-3868.

[55] Grimme, S. Semiempirical GGA-type Density Functional Constructed with a Long-Range Dispersion Correction. J. Comput. Chem., 2006, 27, 1787-1799.

[56] Soler, J. M.; Artacho, E.; Gale, J. D.; García, A.; Junquera, J.; Ordejón, P.; Sánchez-Portal, D. The SIESTA Method for Ab Initio Order-N Materials Simulation. J. Phys.: Condens. Matter., 2002, 14, 2745-2779.

[57] Valiev, M.; Bylaska, E. J.; Govind, N.; Kowalski, K.; Straatsma, T. P.; Van Dam, H. J.; Wang, D.; Nieplocha, J.; Apra, E.; Windus, T.; et al. NWChem: A Comprehensive and Scalable Open-Source Solution for Large Scale Molecular Simulation. Comput. Phys. Commun., 2010, 181, 1477-1489.

[58] Ruiz-Delgado, M. C.; Pigg, K. R.; da Silva Filho, D. A.; Gruhn, N. E.; Sakamoto, Y.; Suzuki, T.; Malavé Osuna, R.; Casado, J.; Hernández, V.; López Navarrete, J. T.; et al. Impact of Perfluorination on The Charge-Transport Parameters of Oligoacene Crystals. J. Am. Chem. Soc., 2009, 131, 1502-1512.

[59] Sakamoto, Y.; Suzuki, T.; Kobayashi, M.; Gao, Y.; Fukai; Inoue, Y.; Sato, F.; Tokito, S. Perfluoropentacene: High-performance p-n Junctions and Complementary Circuits with Pentacene. J. Am. Chem. Soc., 2004, 126, 8138-8140.

[60] Thorley, K. J.; Risko, C. Mapping the Configuration Dependence of Electronic Coupling in Organic Semiconductors. J. Mat. Chem. C., 2016, 4, 3825-3832.

[61] J-H. Dou, J-Q. D. Zheng, Z-F. Yao, Z-A. Yu, T. Lei, X. Shen, X-Y. Luo, J. Sun, S-D. Zhang, Y-F. Ding, G. Han, Y. Yi, J-Y. Wang, J. Pei. J. Am. Chem. Soc., 2015, 137, 15947-15956.

16 
[62] Cheng, X.; Noh, Y. Y.; Wang, J.; Tello, M.; Frisch, J.; Blum, R. P.; Vollmer, A.; Rabe, J. P.; Koch, N. T.; Sirringhaus, $H$. Controlling Electron and Hole Charge Injection in Ambipolar Organic Field-Effect Transistors by Self-Assembled Monolayers. Adv. Funct. Mater., 2009, 19, 2407-2415.

[63] Amy, F.; Chan, C.; Kahn, A. Polarization at The Gold/Pentacene Interface. Org. Electron., 2005, 6, 85-91.

[64] Scott, L. T. Chemistry at The Interior Atoms of Polycyclic Aromatic Hydrocarbons. Chem. Soc. Rev., 2015, 44, 6464-6471.

[65] Greiner, M. T.; Chai, L.; Helander, M. G.; Tang, W. M.; Lu, Z.-H. Transition Metal Oxide Work Functions: The Influence of Cation Oxidation State and Oxygen Vacancies. Adv. Funct. Mater., 2012, 22, 4557-4568.

[66] Greiner, M. T.; Lu, Z.-H. Thin-film Metal Oxides in Organic Semiconductor Devices: Their Electronic Structures, Work Functions and Interfaces. NPG Asia Mater., 2013, 5, 1-16.

[67] Sworakowski, J.; Ulański, J. Electrical properties of organic materials. Annu. Rep. Prog. Chem., Sect. C: Phys. Chem., 2003, 99, 87-125.

[68] Fenwich, O.; Van Dyck, C.; Murugavel, K.; Cornil, D.; Reinsders, F.; Haar, S.; Mayor, M.; Cornil, J.; Samori, P. Modulation the Charge Injection in Organic Field-Effect Transistors: Fluorinated Oligophenyl SelfAssembled Monolayers for High Work Function Electrodes. J. Mater. Chem. C., 2015, 3, 3007-3015.

[69] Helander, M. G.; Wang, Z. B.; Qiu, J.; Greiner, M. T.; Puzzo, D. P.; Liu, Z. W.; Lu, Z. H. Chlorinated Indium Tin Oxide Electrodes with High Work Function for Organic Device Compatibility. Science, 2011, 332, 944-947.

[70] Cardia, R.; Malloci, G.; Bosin, A.; Serra, G.; Cappellin, G. Computational Investigation of the Effects of Perfluorination on The Charge-Transport Properties of Polyaromatic Hydrocarbons. Chem. Phys., 2016. Doi. http://dx.doi.org/10.1016/i.chemphys.2016.06.015

[71] Fan, J-X.; Chen, X-K.; Zhang, S-F.; Ren, A-M. Theoretical Study on Charge Transport Properties of Intraand Extra-Ring Substituted Pentacene Derivatives. J. Phys. Chem. A., 2016, 120, 2390-2400.

[72] Chen, H. Y.; Chao, I. Effect of Perfluorination on The Charge-Transport Properties of Organic Semiconductors: Density Functional Theory Study of Perfluorinated Pentacene and Sexithiophene. Chem. Phys. Lett. 2005, 401, 539-545.

[73] Chen, X. K.; Zou, L. Y.; Gou, J. F.; Ren, A. M. An Efficiente Strategy for Designing $n$-Type Organic Semiconductor Material - Introducing a Six-Members Imide Ring into Aromatic Diimides. J. Mater. Chem., 2012, 22, 6471-6484.

[74] Liu, L.; Yang, G.; Duan, Y.; Gen. Y.; Wu, Y.; Su, Z. A. The Relationship Between Intermolecular Interactions and Charge Transport Properties of Trifluormethylated Polycyclic Aromatic Hydrocarbons. Org. Electron., 2014, 15, 1896-1905. 